\title{
Formación de la identidad "víctima" en el discurso del presidente Juan Manuel Santos sobre la justicia transicional en Colombia 2012-2016
}

\author{
Formation of the "victim" identity in President Juan Manuel Santos' discourse \\ on transitional justice in Colombia 2012-2016 \\ Juan Ruiz Celis \\ Universidad Nacional de Colombia \\ jjruizc9@gmail.com
}

\begin{abstract}
Resumen
El proceso transicional colombiano comprende el periodo que se dio entre el inicio de los diálogos de paz entre el Estado colombiano y las Fuerzas Armadas Revolucionarias de Colombia (FARC), y el momento de la firma del Acuerdo Final para la Terminación del Conflicto. Este proceso tuvo lugar en un contexto de discusiones entre diferentes fuerzas políticas, dentro del cual se definieron los principales lineamientos de la política de paz que implementaría el gobierno. En este marco, este artículo se propone explorar cómo se construyó la identidad de la víctima en el discurso del expresidente de Colombia Juan Manuel Santos sobre la paz y la justicia transicional, en el periodo comprendido entre el 12 de octubre de 2012 (fecha del inicio de los diálogos de paz) y el 24 de noviembre de 2016 (fecha de la firma del Acuerdo de Paz). Se busca identificar, de manera general, algunas relaciones entre los actos semióticos que son desplegados en el discurso del expresidente Santos y las relaciones de poder a las que dan lugar estos actos semióticos, o a las cuales responden.
\end{abstract}

Palabras clave: víctima, justicia transicional, discurso, semiótica, acuerdo de paz

\begin{abstract}
The Colombian transitional process covers the period between the beginning of the peace talks between the Colombian state and the Colombian Armed Revolutionary Forces (FARC), and the signing of the Final Agreement for the End of the Conflict. This process took place in a context of discussions between different political forces, upon which the peace policy guidelines were defined and would be implemented by the government. Building upon this framework, this article explores how the victim's identity was constructed in former Colombian President Juan Manuel Santos' discourses on peace and transitional justice, in the period between October 12, 2012 (date of the start of the peace talks) and November 24, 2016 (date of the signing of the Peace Agreement). It seeks to identify, in general terms, some of the relationships between the semiotic acts that are deployed in former President Santos' discourse and the power relations to which these semiotic acts give rise to, or to which they respond.
\end{abstract}

Keywords: victim, transitional justice, discourse, semiotics, peace agreement

Fecha de recepción: 12 de noviembre de 2019 | Fecha de aceptación: 20 de enero de 2020

Cómo citar este artículo (MLA): Ruiz Celis, Juan. "Formación de la identidad 'víctima' en el discurso del presidente Juan Manuel Santos sobre la justicia transicional en Colombia 2012-2016". Estudios del Discurso 6.1 (2020): 104-128. 
Formación de la identidad "víctima" en el discurso del presidente

\section{Introducción}

El proceso transicional colombiano que se dio entre el inicio formal de los
diálogos de paz entre el Estado colombiano y las Fuerzas Armadas Revolucionarias de Colombia (FARC), y el momento de la firma del Acuerdo Final para la Terminación del Conflicto, tuvo lugar en un contexto de discusiones, acuerdos y disensos entre diferentes fuerzas políticas. Este proceso se enmarcó en pugnas en las que estuvieron involucrados, por lo menos, tres tipos de actores: por una parte, una élite liberal que ha promovido y defendido el proceso de paz entre el Estado y las FARC, al interpretar la paz como una promesa de desarrollo económico futuro. En segundo lugar, un sector conservador que se opone, argumentando que el Acuerdo de Paz favorece la impunidad, incentiva la criminalidad y genera riesgos para las fuerzas de seguridad del Estado y para sectores económicos. En tercer lugar, la unión de distintos sectores progresistas y de izquierda que consideran que el Acuerdo permite una mayor participación de los sectores políticos disidentes en los asuntos públicos.

En este contexto, se generó una discusión sobre quiénes deberían estar autorizados para reclamar por los hechos que tuvieron lugar con ocasión del conflicto armado y las condiciones para su reconocimiento como sujetos reclamantes, lo cual pareció resolverse en el eslogan de gobierno relativo a la "centralidad de las víctimas". En este periodo, el gobierno propuso mecanismos de interlocución entre el Estado y los sujetos definidos como víctimas, que promovieron ideas políticas que, de acuerdo con este análisis, parecían querer salvaguardar los consensos de las élites del país. Este artículo se propone explorar la forma como se construyó la identidad de la víctima en el discurso del expresidente de Colombia Juan Manuel Santos sobre la paz y la justicia transicional, en el periodo comprendido entre el 12 de octubre de 2012 (fecha del inicio formal de los diálogos de paz) y el 24 de noviembre de 2016 (fecha de la firma del Acuerdo de Paz). Se busca identificar, de manera general, algunas relaciones entre los actos semióticos que son desplegados en el discurso del expresidente Santos y las relaciones a las que dan lugar estos actos semióticos, o a las cuales responden. 
Juan Ruiz Celis

\section{Formulaciones conceptuales}

Las luchas por la reconstrucción de Colombia han concitado controversias en torno a la comprensión de los efectos de la violencia experimentada en el marco de una guerra de larga duración, cuyos más de cincuenta años dieron lugar a diferentes victimizaciones y a fracturas en el tejido social. Estos debates han girado en torno a la manera como se entiende el conflicto armado interno, las responsabilidades históricas que son atribuibles a los diferentes actores o el lugar que se asigna a quienes experimentaron las violencias (Sánchez; Gómez-Muller). La producción de sentidos sobre el pasado adquiere especial relevancia en el escenario de implementación del Acuerdo de Paz, toda vez que las categorías emergentes enmarcan los procesos de construcción de las agendas públicas. Las agendas públicas están compuestas por el conjunto de discursos, representaciones sociales y reglas de producción semióticas en razón de las cuales los agentes sociales enuncian, comprenden, interpretan, priorizan y abordan los problemas sociales objeto de actuación (Roth; Pardo y Ruiz).

Temas como la paz, la guerra, el desarrollo, el bienestar y los derechos de las víctimas están en el núcleo de las agendas públicas. Estos temas irrumpen como elementos prescriptivos a instancia de los cuales se sugieren rutas de acción posibles, por lo que integran el campo estratégico en el que los distintos agentes sociales luchan por establecer relaciones que van de la definición del pasado, pasando por la intervención sobre el presente, hasta llegar a la proyección de un prospecto de futuro (Wodak). Los procesos de producción y circulación del discurso tienen repercusiones sobre las formas como se determinan las relaciones entre los agentes sociales y sobre lo que en un momento socio-histórico es representado como prioridad social y, por tanto, es incluido en la agenda pública.

En este trabajo se asume que la articulación entre las prácticas de producción semiótica y las prácticas que emergen en los distintos ámbitos de la vida social se genera en el marco de procesos de poder, que operan a través de la estabilización

de representaciones actualizadas discursivamente (Fairclough). Siguiendo a Pardo Abril, el discurso se entiende como un complejo y simultáneo conjunto de acciones semióticas, soportadas y amplificadas en distintos sistemas de signos, en cuyo 
Formación de la identidad "víctima" en el discurso del presidente

proceso de construcción de significado producen y reproducen relaciones de poder y de saber, a través de distintos mecanismos de representación de la realidad. El énfasis en el poder y en lo político es razonable si se define este último, en un sentido amplio, como el espacio de emergencia e interrelación de relaciones de poder, que estructura el campo decisional en el que se define el acceso a los recursos de representación política y de acción pública.

La formación de la identidad "víctima" se inscribe en prácticas de producción discursiva de la identidad y la subjetividad, en razón de las cuales a los sujetos se les asigna existencia social, se definen los rasgos que les diferencia de otros sujetos y se construyen patrones que les permite interactuar entre sí. La producción de identidad es un proceso a través del cual se da cuenta de la forma como las relaciones de poder construyen las condiciones de formación de los sujetos y definen la trayectoria potencial de sus marcos experienciales. La modulación de las prácticas y del horizonte de la experiencia subjetiva se lleva a cabo a través de regulaciones que condicionan la formación de la personalidad, y mediante las construcciones referenciales que dichos sujetos toman como base para actuar conjuntamente (Mercado y Hernández).

La articulación entre los procesos de formación de la identidad y las prácticas de poder se verifica en la forma como los sujetos internalizan los saberes que se construyen y distribuyen discursivamente y en razón de lo cual emergen formas de (auto)regulación. La hipótesis de Butler es que "el poder que en un principio aparece como externo, presionando sobre el sujeto, presionando al sujeto a la subordinación, asume una forma psíquica que constituye la identidad del sujeto". Los mecanismos reguladores a través de los cuales opera el poder toman como eje la conversión de la norma - producida y estabilizada semióticamente- en una matriz productora de la realidad psíquica del sujeto. La subjetividad emerge en relación con prácticas de poder, que, al mismo tiempo que producen y restringen el universo experiencial y delimitan el horizonte de sociabilidad vivible, potencian el ejercicio de prácticas disruptivas. El sujeto, por consiguiente, lejos de ser una entidad acabada y determinada de forma estática por las relaciones de poder, emerge de procesos de producción permanentes y dinámicos, que tienen como propósito la formación del Yo, en concordancia con imperativos éticos y prácticos instalados en el universo semiótico. 
El Estado, sus instituciones y sus agentes son algunos de los actores más importantes en la definición de las agendas públicas, por disponer de abundantes recursos de representación (Chilton y Schäffner; Van Dijk); no obstante, éste es un proceso complejo en el que participan distintos tipos de actores, en cuyas interrelaciones se definen los ideales que las autoridades públicas toman en consideración a la hora de intervenir sobre los problemas sociales (Fairclough y Fairclough). El discurso presidencial se constituye en una evidencia de las representaciones que son jerarquizadas por las autoridades público-estatales, los ejes conceptuales que sostienen la acción del Estado y las direcciones hacia donde apuntan los procesos de intervención; al mismo tiempo, dado el acceso privilegiado que tiene a los medios de representación, ejerce una intensa actividad performativa, modeladora de la realidad social. Los discursos presidenciales se caracterizan por su alto nivel de difusión que tienen en los medios de comunicación y en otros espacios de construcción de lo público, y por los efectos de definición de las formas como se entiende y se asume el acceso a la ciudadanía; en consecuencia, ponen en evidencia los núcleos conceptuales que estructuran la acción pública y los procesos de subjetivación habilitados y promovidos institucionalmente.

\section{Consideraciones metodológicas}

Este trabajo se inscribe en la propuesta metodológica formulada por Pardo Abril y toma como base los principios de los Estudios Críticos del Discurso, según los cuales las relaciones de poder pueden entenderse a través de las representaciones que elaboran los actores sociales en sus discursos, en un momento socio-histórico específico. En razón de este principio, se reconoce que la construcción de la identidad "víctima" se lleva a cabo en el marco de complejos procesos de poder que pueden ser rastreados, entre otros, en los discursos del actor gubernamental de mayor rango: el Presidente. Por esta razón, la muestra objeto de análisis consiste en una selección de cinco discursos extraídos de un corpus más amplio de 114 discursos del expresidente Juan Manuel Santos, producidos y socializados entre el 12 de octubre de 2012 (fecha del inicio formal de los diálogos de paz 
Formación de la identidad "víctima" en el discurso del presidente

entre el Gobierno y las FARC) y el 24 de noviembre de 2016 (fecha de la firma del Acuerdo de Paz).

Los discursos fueron seleccionados de la página web de la Presidencia de la República de Colombia (Santos) a través del buscador, rastreando dos conceptos clave que sirvieron como elementos de identificación: "paz" y "justicia transicional". Los textos objeto de análisis corresponden con las transcripciones de las alocuciones presidenciales que se llevaron a cabo en diferentes escenarios de interlocución. Estos escenarios discursivos incluyen la participación de la ciudadanía y de públicos especializados. Entre los potenciales interlocutores destacan:

- Funcionarios y ejecutores de políticas públicas

- Empresarios y agentes de los gremios económicos

- Periodistas y otros actores vinculados con los medios masivos de comunicación

- Congresistas

- Asistentes a la inauguración de las entidades públicas creadas en el marco del proceso transicional

- Partidos políticos

- Asistentes a eventos en escenarios internacionales

- Miembros de las fuerzas de seguridad del Estado

El proceso de indagación y la selección de las muestras finales se realizó en tres fases interconectadas, para cuyo desarrollo se combinaron técnicas de investigación cualitativas y cuantitativas. En la primera fase se recopiló la muestra de acuerdo con dos criterios: que los discursos presidenciales correspondieran al periodo que va del 18 de octubre de 2012 al 24 de noviembre de 2016, y que cada uno hiciera referencia explícita a los segmentos discursivos "paz" y "justicia transicional". El intervalo temporal que se aborda se caracteriza por una alta producción discursiva mediatizada respecto a lo que podría significar el desarme de las FARC, y sobre los requerimientos de dicho proceso en materia de derechos humanos, memoria, verdad, justicia y restitución de las tierras que fueron despojadas a las víctimas, por parte de los actores armados.

Posterior a la recopilación de la muestra sobre la base de los hitos temporales anteriormente descritos, se llevó a cabo la constitución del corpus y se realizó su procesamiento estadístico, utilizando técnicas de la estadística textual: cálculos de 
frecuencia, co-ocurrencia de unidades léxicas, identificación de segmentos discursivos relevantes y análisis de coeficientes de correlación para determinar asociaciones semánticas. Esto se realizó a través de los softwares T-Lab Plus y Nvivo 11, los cuales permitieron la realización de diversas operaciones de categorización, etiquetado y cuantificación, que facilitaron el manejo de la información. Por razones de extensión, los resultados del análisis estadístico-textual no se describen en este trabajo, pero son un punto de partida para la selección de las muestras objeto de análisis cualitativo.

En la segunda fase, con ayuda de los resultados estadísticos, se lleva a cabo la descripción de la muestra y la puesta en relación de los distintos componentes semiótico-discursivos que la constituyen. Se hace énfasis en la dimensión propiamente cualitativa del discurso y se identifican los recursos y las estrategias discursivas presentes en el corpus. El abordaje cualitativo implícitamente reconoce la insuficiencia de las herramientas cuantitativas para descifrar el conjunto de relaciones semiótico-discursivas inherentes al corpus, por lo que se lleva a cabo su abordaje manual, tomando como punto de referencia las coordenadas visualizadas estadísticamente y los fenómenos que son interpretables a través de la indagación cualitativa de los datos. Este proceso permitió la selección de cinco muestras que concentran recursos y estrategias discursivas que podrían dar cuenta de cómo se construye la identidad "víctima" en los discursos presidenciales objeto de análisis.

En la tercera fase, se ponen en relación las regularidades discursivas evidenciadas en las muestras seleccionadas en la segunda fase, con las condiciones sociales de emergencia de los discursos. Se identifican los campos semántico-pragmáticos estratégicos en los cuales se define la identidad "víctima". Se reconstruyen las representaciones discursivas y su función política, tomando como punto de referencia las axiologías, las identidades de los actores representados, los roles, las normas, los intereses y las estrategias que se deducen de los actos comunicativos. Se analiza el potencial efecto de poder que tiene la acción semiótico-discursiva, tomando en consideración elementos el entorno social e histórico en el que tienen lugar los discursos. 
Formación de la identidad "víctima" en el discurso del presidente

\section{Perspectivas analíticas}

Los discursos presidenciales sobre la justicia transicional ${ }^{1}$ del expresidente de Colombia Juan Manuel Santos se caracterizaron por la reiteración de marcos morales en virtud de los cuales, a los sujetos victimizados, actores frecuentemente referidos en sus alocuciones, se les atribuyen roles, lugares y disposiciones emocionales, que se definen en correspondencia con las directrices políticas del modelo de paz que se perfiló desde su administración. Este conjunto de atribuciones realizadas a los sujetos victimizados integra el conjunto de actos semióticos a instancia de los cuales se formula el discurso sobre las víctimas. Los discursos del expresidente Santos, por tanto, se abordan no en su calidad de actos semióticos motivados por una conciencia individual, sino en la medida en que se insertan en secuencias enunciativas de más amplio espectro, en cuyas relaciones se estabilizan significados a nivel social y, en referencia a ellos, se prescriben relaciones sociales.

La construcción de los marcos epistémicos a través de los cuales se formula la identidad de los sujetos victimizados toma como base el uso de marcadores de emocionalidad, desde los que se interpela a los potenciales interpretantes, procesos de focalización que se apoyan en proposiciones compuestas, estrategias de legitimación y voces discursivas con propósitos de validación argumental. También se observa el uso de enunciados interrogativos con función retórica y axiomas indirectos para proponer acciones e implicaturas orientadas a reinscribir, en el plano de lo subjetivo, prácticas y procesos que se definen en el escenario social de las relaciones de poder, las prácticas de negociación y la construcción de solidaridades colectivas. En el discurso sobre las víctimas los sujetos victimizados son modelados semióticamente como seres inocentes, como sujetos generosos o como individuos que tienen la obligación moral de perdonar.

\footnotetext{
${ }^{1}$ La justicia transicional se entiende como el conjunto de medidas jurídicas y técnico-políticas para superar periodos de violencia casada por conflictos internos o guerras entre estados, en el que se busca generar oportunidades de alternatividad penal para los actores participantes en la confrontación y la construcción de mecanismos para la construcción de paz (Teitel).
} 
Juan Ruiz Celis

En la construcción del discurso sobre las víctimas, se reafirman actitudes socialmente aceptadas, que se proponen como recursos de amplificación de la voz moral del expresidente Santos y, al mismo tiempo, que cumplen la función de estabilizar saberes y valores que refrendan relaciones sociales específicas. La construcción del sujeto victimizado como instrumento de moralización permite al expresidente formular la diferenciación y la jerarquización entre quienes se adhieren a los referentes axiológicos propuestos en el discurso sobre las víctimas y quienes no se ajustan al patrón valorativo producido y validado discursivamente. En este movimiento semiótico-discursivo se modela una política de reconocimiento diferencial, en la que se lleva a cabo un encuadre selectivo de las violencias y de los sujetos que las experimentan. Esta proyección se basa en una ontología del sujeto definido como víctima en la cual la capacidad de nominarlo e inteligirlo está condicionada por las normas de reconocimiento que se estructuran en referencia a prácticas de poder.

\section{La víctima como sujeto inocente}

El análisis del modelado el sujeto representado como víctima remite al proceso de definición de las condiciones para su reconocimiento, en el cual se producen diferenciaciones y distanciamientos sociales, inducidos por los esquemas de inteligibilidad que se formulan a través de los actos semióticos. Las diferenciaciones y los distanciamientos se instituyen como condicionantes de la posibilidad de acceso a los escenarios de interlocución con la que cuentan los sujetos victimizados, la formulación e implementación de políticas públicas para la atención de los diversos grupos de sujetos violentados y la posibilidad de emergencia de vínculos de solidaridad que potencien la construcción de paz y la superación de las fracturas generadas por la guerra. El modelamiento de los sujetos victimizados como seres inocentes, como sujetos generosos o como individuos que están en la obligación moral de perdonar define los límites y las posibilidades de reconocimiento de las distintas experiencias de violencia y delimita el marco al que se circunscribe la agencialidad política de dichos sujetos. 
Formación de la identidad "víctima" en el discurso del presidente

¿Cuántas imágenes hemos visto y cuántos relatos hemos escuchado de la guerra que vivimos hace medio siglo? Creo que es una cuenta imposible de hacer. Lo que sí les digo es que parecen no haber sido suficientes - hasta ahora- para que ToDos comprendamos la tragedia de cientos de miles de víctimas [...]. Sus testimonios nos duelen y nos tocan el corazón, y así debe ser, porque nadie puede quedarse indiferente ante la zozobra de los inocentes a quienes les arrancan sus hijos, sus compañeros o compañeras, sus padres, o los despojan de sus parcelas. (Santos, informe del Centro de Memoria Histórica. 24 de julio de 2013) También quiero rendir homenaje a las millones de víctimas inocentes; a los defensores de derechos humanos; a las comunidades indígenas, afrocolombianas y campesinas; a tantas mujeres y madres que - en medio de las lágrimasabonaron el camino hacia la paz. No MÁs jóvenes sacrificados, no más jóvenes muertos, no más jóvenes mutilados por una guerra absurda... ¡Ni soldados, ni policías, ni campesinos, ni guerrilleros! Las nuevas generaciones de Colombia destinarán sus energías a promover el desarrollo y la felicidad del país. Eso es lo que merecen, iy eso es lo que vamos a hacer posible a partir de hoy! (Santos, acto de firma del Acuerdo Final para la Terminación del Conflicto con las FARC, 26 de noviembre de 2016)

En el modelamiento de la víctima como sujeto inocente se construye semióticamente el sentido de lo trágico, lo cruel y lo injusto y, a través de distintas estructuras modales, se convoca a la adhesión respecto a lo representado discursivamente. El uso discursivo del sujeto victimizado como sujeto de emociones susceptible de experimentar dolor razonable se elabora como recurso de ejemplarización y de homologación de un sentir colectivo, que se proyecta indirectamente como el deber del buen ciudadano.

Preguntas con función retórica como “¿Cuántas imágenes hemos visto y cuántos relatos hemos escuchado de la guerra que vivimos hace medio siglo?" sirven para introducir al interlocutor al campo semántico del dolor y el sufrimiento, así como para justificar la razón por la cual el expresidente toma la palabra. Esto también se lleva a cabo a través de prácticas de memorialización en razón de las cuales emergen los recuerdos de la guerra, las imágenes de la violencia, la presencia de los sujetos victimizados y las situaciones que permitirían identificar algunos de los rasgos del conflicto armado. En el caso de la formulación de la pregunta retórica, se propone indirectamente la voz del expresidente, a través de la reiteración de adjetivos con función de cuantificación, como la expresión de una 
Juan Ruiz Celis

voz colectiva desde la que se tematizan las violencias y los sufrimientos y, al mismo tiempo, se les otorga sentido de realidad. Esta representación le atribuye al expresidente el rol de líder carismático, cuya relación con los distintos estamentos y sectores sociales es mediada por el vínculo afectivo que reafirma discursivamente.

El campo semántico del dolor y el sufrimiento es reforzado también a través de expresiones emocionales que interpelan a los potenciales interlocutores: "imágenes [...] y [...] relatos [...] de la guerra", "la tragedia de cientos de miles de víctimas", "sus testimonios nos duelen y nos tocan el corazón", "la zozobra de los inocentes a quienes les arrancan sus hijos, sus compañeros o compañeras, sus padres, o los despojan de sus parcelas", "mujeres y madres que — en medio de las lágrimasabonaron el camino hacia la paz", "jóvenes sacrificados, [...] jóvenes muertos, [...] jóvenes mutilados", entre otras. Estos recursos de interpelación emocional inducen a la formación de actitudes respecto a los sujetos victimizados, que se basan en la construcción y revalidación de creencias que focalizan sobre la dimensión emocional de dichos sujetos y no sobre su potencialidad política o sobre la necesidad de la construcción social de un reconocimiento que exceda su representación como sujetos testimoniantes de su propio dolor.

El dolor y el sufrimiento como marcos experienciales también se representan a través de marcadores de deixis temporal desde los que se sugiere la transformación en la constante histórica de desconocimiento de los sujetos victimizados y se formula la localización e identificación temporal de propuestas, procesos y acontecimientos, en relación con el contexto semióticamente modelado. En "[Las imágenes y los relatos sobre la guerra] parecen no haber sido suficientes - hasta ahora- para que TODos comprendamos la tragedia de cientos de miles de víctimas", a través del marcador de indexicalidad focalizado mediante el uso de los guiones, se sugiere un cambio en la trayectoria política del gobierno, con el propósito de construir empatía a través de la simulación de la conexión emocional entre el expresidente y los sujetos victimizados. La construcción de empatía se apoya en recursos de modalización epistémica y el uso de cuantificadores que tienen como propósito amplificar semánticamente el valor argumentativo de lo que se expresa.

El uso de los cuantificadores es central en los procesos de representación de los sujetos victimizados, ya que contribuye a la construcción de una tópica de la emoción, en el sentido expuesto por Charaudeau, en la que las magnitudes o estimativos 
Formación de la identidad "víctima" en el discurso del presidente

focalizan sobre el supuesto sentir general en torno a la situación de un grupo de actores sociales, cuya atención se justifica indirectamente en función de la compasión a la que convocaría la cantidad de personas afectadas por la guerra.

Cuantificadores universales con función pronominal, como en el caso de "para que toDos comprendamos", el cual se focaliza a través de realces prosódicos en letras mayúsculas; o estructuras cuantificadas indeterminadas como "la tragedia de cientos de miles de víctimas", en las cuales el operador no remite a una magnitud definible; refuerzan una relación en la que se lleva a cabo un doble movimiento semiótico. Por una parte, la construcción del sentido de unidad grupal en razón de la cual el expresidente y los distintos grupos sociales son propuestos en el mismo nivel jerárquico, de lo cual se sugiere la existencia de una comunidad de afecto. Por otra parte, la definición de un grupo social en el que los sujetos que lo componen, sin nombres ni identidades que remitan directamente a sus experiencias, son formulados como portadores de la tragedia, del sufrimiento y del dolor.

La construcción de la idea de comunidad de afecto se reafirma a través de recursos de modalización deóntica - mediante los cuales Juan Manuel Santos expresa mandato, obligación y deseo- y a través de focos formulados mediante incisos demarcados sintácticamente, con lo cual lleva a cabo actos de habla con función exhortativa o apelativa. El uso de marcadores de emocionalidad permite la construcción de referentes de legitimación en virtud de los cuales lo trágico y lo cruel se proponen como campos en los que confluye la afectividad de los potenciales interpretantes, la de los sujetos victimizados sobre quienes recae el infortunio de la violencia y la del expresidente, quien se postula como el agente capaz de enunciar el sentir común. La afectividad evocada se modela a través de la construcción de la víctima como el sujeto de la injusticia, lo cual, mediante metáforas ontológicas como "nadie puede quedarse indiferente ante la zozobra de los inocentes a quienes les arrancan sus hijos, sus compañeros o compañeras, sus padres, o los despojan de sus parcelas", desplaza del plano representacional la capacidad de agencia de los sujetos victimizados, sobre quienes recae la acción de terceros que no se identifican.

En la construcción de la víctima inocente también se emplean referentes de vinculación filial con los que se dota de legitimidad a la relación afectiva que se propone discursivamente, en la cual, a través de los roles actanciales con función 
Juan Ruiz Celis

icónica, se formula el sentido de vulnerabilidad y debilidad. El modelamiento actancial de la víctima inocente, cuyos potenciales roles se elaboran a través de nominales colectivos determinados como "defensores de derechos humanos", "comunidades indígenas, afrocolombianas y campesinas", "mujeres y madres", “jóvenes sacrificados", “jóvenes muertos”, “jóvenes mutilados”, "soldados”, “policías” y "guerrilleros", define un rango de potenciales lugares de victimización, que son validados a través de la voz del expresidente. Los lugares de validación en la secuencia discursiva se elaboran movilizando referentes cuya jerarquía decrece a medida que ocupan los lugares finales, en razón del modelamiento focal que con frecuencia asigna mayor valor a los primeros términos de la cláusula y resta valor al resto de la información.

La construcción de los nominales colectivos determinados permite la designación de conjuntos homogéneos de personas, que comparten elementos que funcionan como identificadores. Estas construcciones discursivas permiten la puesta en escena de grupos nominales complejos con función atributiva y persuasiva, los cuales, a través de la articulación de determinantes, destacan características particulares de los sujetos referenciados en el discurso. En las expresiones "mujeres y madres que - en medio de las lágrimas- abonaron el camino hacia la paz", "jóvenes sacrificados”, “jóvenes muertos”, “jóvenes mutilados”, "guerra absurda”, entre otras, se modelan grupos nominales, algunos de los cuales se metaforizan y se construyen con aposiciones explicativas, que indicen a centrar la atención sobre los determinantes. En estas construcciones, los atributos son jerarquizados semánticamente $y$, en consecuencia, la identidad de los sujetos nominados es definida en función de dichos atributos. En este caso, las mujeres y las madres son definidas en función de su relación con el dolor, el cual se propone como referente de construcción de paz; los jóvenes se construyen como depositarios de violencias extremas; y a la guerra se le atribuyen rasgos humanos y, por esta vía, se convierte en sujeto de acción.

La refrendación del modelo transicional se efectúa cuando, al amparo del modelamiento de la víctima inocente, se construye un futuro diseñado a través de la activación de referentes legitimados socialmente y del uso de tiempos verbales que indican certeza de la acción: "Las nuevas generaciones de Colombia destinarán sus energías a promover el desarrollo y la felicidad del país. Eso es lo que merecen, 
Formación de la identidad "víctima" en el discurso del presidente

¡y eso es lo que vamos a hacer posible a partir de hoy!". En esta estructura, el uso del verbo en futuro del modo indicativo "las nuevas generaciones de Colombia destinarán sus energías" elabora el sentido de predicción y formula una promesa sobre la cual se construye una expectativa positiva, apoyada en la evocación de unidades conceptuales como "desarrollo" y "felicidad", que expresan deseos colectivos. Si bien esta construcción discursiva define un horizonte de acción futuro, desempeña una función de resemiotización en virtud de la cual el marco conceptual del sufrimiento de la guerra y del acuerdo en torno al deber afectivo con los sujetos victimizados es rediseñado en correspondencia con la refrendación de la felicidad en torno al logro del desarrollo, el cual no se problematiza como categoría en disputa que contribuyó a la persistencia del conflicto armado.

\section{La víctima como sujeto generoso}

La construcción de la víctima inocente se lleva a cabo en correspondencia con la definición de la víctima como sujeto generoso, la cual no solo se propone como referente conductual, sino que se constituye en un caracterizador de quienes estarían habilitados para dar "lecciones de humanidad", en virtud de su aceptación del marco moral propuesto. En este marco, los sujetos victimizados, cuyas voces son refrendadas en razón de su rol como testigos experienciales de las violencias, se convierten en instancias de legitimación del perdón y la reconciliación como horizontes de construcción de paz, y se formulan como sujetos dispuestos a renunciar a una parte de su derecho a la justicia y a conformarse con la reparación simbólica que procedería del acceso a la verdad. La manera como se construye la reparación simbólica se propone en correspondencia con formas de racionalización en las que el régimen moral sugiere como irrazonable la exigencia de la reparación material y de la transformación de las relaciones de poder que se expresan en la distribución segmentada y estratificada del acceso a los recursos materiales.

$\mathrm{Y}$ yo quisiera resaltar algo: mientras algunos miembros de la sociedad critican el proceso de paz y solo contemplan la continuación de esta guerra, de esta absurda guerra, o una inconcebible rendición incondicional de la guerrilla, son las víctimas las que nos dan lecciones de humanidad, de reconciliación y de 
perdón. Las víctimas - que han sufrido en carne propia el conflicto- son las más generosas, porque saben que solo la paz impedirá que otros sufran lo que ellas sufrieron. (Santos, vento sobre paz y reconciliación. 30 de octubre de 2014) Tomamos una decisión muy audaz, que fue [...] mandar representantes de las víctimas a hablar con los negociadores, a que ellos expresen cómo este proceso puede satisfacer sus derechos. Y es un ejercicio o fue un ejercicio maravilloso, muy criticado al principio, pero yo creo que hoy nadie puede decir que resultó malo. Todo lo contrario. Para mí fue muy importante ver cómo las víctimas regresaban y me decían, esta experiencia maravillosa para mí me cambia la vida. Recuerdo una víctima que me dijo: 'yo lo único que quería en la vida era que este señor que mató a mi familia me lo dijera en la cara y me pidiera perdón. Era lo único que yo quería y eso se dio'. Y en términos generales las víctimas están siendo más generosas que la población en general en materia de qué representa o qué puede satisfacer sus derechos en materia de justicia porque si conocen la verdad, son reparadas simbólicamente, porque no puede uno sino reparar simbólicamente, porque cuánto vale un hijo, una hija, cuánto vale la familia. No tiene precio. Cualquier reparación es simbólica [...]. (Santos, conmemoración de los 24 años de Bancóldex, 18 de febrero de 2015)

En la propuesta causal que formula el discurso, amplificada a través de la expresión modalizada con función focal "quisiera resaltar", la crítica al proceso de paz se propone como una práctica que va en concordancia con la continuidad de una guerra a la que se le atribuye el carácter de absurda y contraria a los valores e intereses de los sujetos victimizados. En esta expresión, el sentido de oposición se elabora a través de construcciones proposicionales como "mientras algunos miembros de la sociedad critican [...] son las víctimas las que nos dan lecciones de humanidad, de reconciliación y de perdón”. Estas formas de modelamiento semiótico ponen en relación procesos de construcción de agencialidades grupales, en las cuales, los sujetos que son evocados a través de la estructura nominal indeterminada "algunos miembros de la sociedad", son enfrentados a otros actores también definidos de forma genérica, a quienes se les asigna, paradójicamente, el lugar de la experiencia.

En la construcción discursiva de los sujetos indeterminados - "algunos miembros de la sociedad" - , indistintamente del sector social de donde podrían provenir las críticas al proceso de paz, los distintos e incluso divergentes posicionamientos de agentes que se ubican en diversos lugares sociales son 
Formación de la identidad "víctima" en el discurso del presidente

equiparados como si su base común fuese la obstaculización de la paz. En este proceso de construcción de equivalencia se establecen legitimadores indirectos, a partir de los cuales se propone como válida la clausura de los espacios de interlocución no solamente para los sectores políticos Uribistas, a quienes el Gobierno acertadamente ha atribuido el lugar de obstrucción del proceso de paz, sino también respecto a otros sectores sociales que han cuestionado los puntos incluidos por el gobierno y las FARC en la agenda de la negociación. La nominalización indeterminada se constituye en un recurso de encuadramiento ideológico y de construcción de un consenso que se propone centrado en los intereses que el expresidente ha expresado en torno al modelo transicional.

En el caso de los sujetos victimizados, también definidos de forma genérica, Juan Manuel Santos se propone como defensor de los intereses de quienes han sido violentados en el marco del conflicto. En la construcción de la oposición entre quienes quieren paz - cuyo representante con mayor reconocimiento discursivo es el sujeto definido como víctima - y quienes se supone que estarían a favor de la guerra, se lleva a cabo la eliminación representacional y la neutralización política de los sujetos victimizados por el Estado, muchos de los cuales no se sienten identificados con el pacto simbólico que han construido los grupos dominantes en torno al perdón y la reconciliación. La eliminación simbólica de las víctimas del Estado y su neutralización política se modela a través de la construcción de las voces discursivas de sujetos victimizados, agrupados a través de categorizaciones abstractas, desde las cuales se refrenda el modelo transicional y se desacreditan las posibles resistencias de sectores sociales no coincidentes políticamente con el proyecto uribista: "Las víctimas - que han sufrido en carne propia el conflicto- son las más generosas, porque saben que solo la paz impedirá que otros sufran lo que ellas sufrieron". El uso de categorías genéricas, por consiguiente, permite la negación de una parte de los sujetos victimizados y se constituye en la base para la funcionalización de sus voces y su usufructo político.

El proceso de homologación de la voz discursiva del expresidente y la de los sujetos definidos como víctimas se lleva a cabo a través de la puesta en escena de procesos semánticos de ubicación intragrupal través de la pluralización de la primera persona y a través de atributivos desde los que se construyen expresiones predicativas que denotan la disposición afectiva de Juan Manuel Santos: “Tomamos una decisión muy audaz, que fue [...] mandar representantes de las víctimas a 
hablar con los negociadores, a que ellos expresen cómo este proceso puede satisfacer sus derechos". En estas construcciones discursivas, a través de procesos atributivos de modificación nominal que se apoyan en cuantificadores de grado construidos mediante expresiones adverbiales, el expresidente propone para sí y para su grupo de pertenencia un conjunto de cualidades que son socialmente validadas (astucia, osadía y atrevimiento), lo cual construye los sentidos de inteligencia, sagacidad e innovación, que revisten a la figura presidencial de las características del líder carismático. Esta representación elide el papel activo que tuvo el movimiento de sujetos victimizados en la reivindicación de su derecho a la participación en las mesas de negociación entre el Estado y las FARC.

La construcción de la figura presidencial se acompaña de expresiones modalizadas en las que se activan representaciones sociales positivas que enmarcan afectiva y moralmente lo que se propone: "satisfacer [...] derechos [de las víctimas]", "fue un ejercicio maravilloso", "hoy nadie puede decir que resultó malo", "para mí fue muy importante”, “[...] las víctimas [...] me decían, esta experiencia maravillosa para mí me cambia la vida”, entre otras. En estas construcciones, procesos de atribución que convocan la aprobación de la acción y formas de modalización deóntica que expresan prohibición se combinan como orientadores y modeladores de la atención hacia lo que se recoge en el testimonio de un sujeto victimizado cuya identidad no se explicita: " "yo lo único que quería en la vida era que este señor que mató a mi familia me lo dijera en la cara y me pidiera perdón. Era lo único que yo quería y eso se dio»".

En esta voz discursiva, la interpretación del interés del sujeto victimizado tiene la función de desfocalizar y deslegitimar las demandas de justicia del movimiento de víctimas, sobre la base de la actitud moral que se sugiere correspondiente con el propósito del logro de la paz. En la voz discursiva se formulan los sentidos de honor y valor a través de construcciones demostrativas que apropian deícticos personales que se inscriben en contextos discursivos de modalización - "yo lo único que quería en la vida [...]"- - El diseño de los sentidos de honor y valor también se lleva a cabo mediante complementos que expresan deseo y desde los que se perfila la acción contestataria frente a quien se propone como victimario: "[...] que este señor que mató a mi familia me lo dijera en la cara y me pidiera perdón. Era lo único que yo quería y eso se dio". Los códigos de honor que se 
Formación de la identidad "víctima" en el discurso del presidente

activan en el discurso focalizan sobre las cualidades que conllevan al cumplimiento de deberes que se proponen moralmente elevados y que conducen a la virtud, al reconocimiento social y a la buena reputación. El sentido del valor sugiere firmeza, fuerza, vitalidad y eficacia, y denota osadía y heroísmo en la toma de decisiones y en la realización de grandes acciones.

Los sentidos de honor y de valor que se les atribuye a los sujetos victimizados a través de la voz del sujeto testimonial se constituyen en reforzadores axiológicos desde los cuales la generosidad se formula como el horizonte moral a seguir. La refrendación del valor de la generosidad y su atribución a la totalidad de los sujetos victimizados se propone como un recurso desde el cual se elabora una racionalización que vincula los principios de justicia, verdad y reparación en una perspectiva minimalista, en razón de la cual, so pretexto del acceso a la verdad y a la reparación simbólica, es minimizada la responsabilidad estatal de garantizar el derecho a la justicia y a la dimensión material de la reparación. Como contrapartida, se hace recaer sobre los sujetos victimizados el deber de fomentar la actitud correspondiente con el marco moral propuesto, mediante el uso de recursos semiótico-discursivos como las preguntas con función retórica: “[...] en términos generales las víctimas están siendo más generosas que la población en general en materia de qué representa o qué puede satisfacer sus derechos en materia de justicia, porque si conocen la verdad son reparadas simbólicamente $[. .$.$] porque$ cuánto vale un hijo, una hija, cuánto vale la familia. No tiene precio. Cualquier reparación es simbólica [...]”.

La víctima como sujeto que tiene la obligación de perdonar

La construcción de la víctima como sujeto generoso es la base de representaciones de los sujetos victimizados en las que se les propone como seres caracterizados por una autoridad moral que procede de su capacidad de perdón y reconciliación. El modelamiento semiótico del sujeto perdonador se propone como antecedente para la reformulación de marcos de moralidad que, en este caso, funcionan activando intertextos desde los que se proponen dos equivalencias bipartitas en relación de oposición: paz y perdón vs. guerra y resentimiento. En estas construcciones discursivas, la referencia a los sujetos victimizados se utiliza como un recurso 
Juan Ruiz Celis

ejemplarizante que no solamente se orienta a la movilización emocional y a la orientación de las prácticas sociales, sino que, de manera indirecta, impone sobre los sujetos victimizados la obligación moral de perdonar y de reconciliarse, como si fuesen requisitos para la construcción de paz.

El perdón y la reconciliación, en el discurso del expresidente, se formulan como rasgos que parecieran ser consubstanciales a ciertos tipos de sujetos que se inclinan más que otros a la satisfacción de los códigos morales que se formulan.

Las Víctimas, en el caso colombiano, las quisimos colocar en el centro de la solución del conflicto, porque son las Víctimas las que nos deben enseñar [...] a perdonar, a reconciliarse. Son las que tienen la mayor autoridad moral para hacerlo. [...]. La paz comienza en nuestros propios corazones, cuando uno está en paz con uno mismo tiene mucha más posibilidad de hacer la paz con otros. La paz comienza también cuando uno aprende a perdonar, eso es muy importante. Los colombianos, por haber vivido tanto tiempo en guerra, se nos había olvidado perdonar $\mathrm{y}$ fuimos acumulando resentimientos o visiones de la guerra poco a poco, en el subconsciente muchas veces, que nos hace muchas veces ser mucho más duros, y ahí yo tuve una lección de vida de parte precisamente de las víctimas. [...] yo pensaba que en esa justicia transicional que estábamos diseñando, las víctimas iban a ser las que más endurecidas se iban a mostrar cuando, por ejemplo, discutiéramos dónde trazar la línea entre justicia y paz. Y las Víctimas me han enseñado que estaba muy equivocado. Las más generosas, las que han resultado mucho más propensas a perdonar, a reconciliarse con sus victimarios, son ellas, comparándolas con el promedio de la población que muchas veces no ha sentido en carne propia los efectos de la guerra. [...] Todas esas Víctimas son las que nos van a señalar el camino al resto, a decir miren nosotros estuvimos en la guerra, sufrimos la guerra pero fuimos capaces [...] de perdonar, fuimos capaces de rehacer nuestras vidas, fuimos capaces de dejar atrás ese inmenso dolor, ese inmenso sufrimiento que causamos y que nos causaron para que todos juntos podamos trabajar hacia adelante por un mejor país. (Santos, foro Construyendo un Futuro de Reconciliación, 19 de abril de 2016)

En la representación de los sujetos victimizados como actores del perdón y la reconciliación se articulan diversos recursos que, al tiempo que establecen atribuciones, insinúan la acción público-estatal como si fuese subsidiaria a los designios 
Formación de la identidad "víctima" en el discurso del presidente

del expresidente y su equipo de gobierno. En este modelamiento semiótico, el reconocimiento de los derechos de los sujetos victimizados se propone como si fuese producto de favorecimientos personales de Juan Manuel Santos a través del uso del recurso verbal de la primera persona del plural y de modalizadores deónticos. Estos recursos sugieren sentido de obligatoriedad en expresiones como "Las Víctimas [...] las quisimos colocar en el centro de la solución del conflicto, porque son las Víctimas las que nos deben enseñar [...]", desde las cuales el expresidente perfila sus estrategias de relacionamiento con los sujetos victimizados.

La atribución de la responsabilidad del logro de la paz a los sujetos victimizados se define a través de la construcción de estructuras cuantificadas comparativas ("[Las víctimas] son las que tienen la mayor autoridad moral para hacerlo") y el modelamiento de formas de legitimación a través de la construcción de la autoridad derivada de la experiencia ("yo tuve una lección de vida de parte precisamente de las víctimas" y "Las más generosas [...] son ellas, comparándolas con el promedio de la población que muchas veces no ha sentido en carne propia los efectos de la guerra"). Estos recursos, desde los cuales aparentemente se reconoce el potencial de los sujetos victimizados para la acción, solo toma en cuenta la experiencia de dichos sujetos en tanto seres afectados por la violencia que pueden reconstruir sus vidas a través de la revalidación de marcos que han sido cuestionados en diferentes contextos sociales. En este sentido, en el discurso se lleva a cabo una estrategia de normalización axiológica que se sustenta sobre el supuesto carácter de guías morales de las víctimas en tanto sujetos generosos y perdonadores, con la autoridad conferida por la humildad (que se supone les es inherente) de sugerir el destino colectivo de la nación.

La apelación al recurso del intertexto religioso usualmente denota el reforzamiento de saberes jerárquicamente ubicados en el espectro cultural, desde los que adquieren relevancia emociones, reflexiones y procesos de introspección individuales, que se refrendan como horizontes de construcción de lo colectivo: "La paz comienza en nuestros propios corazones, cuando uno está en paz con uno mismo tiene mucha más posibilidad de hacer la paz con otros. La paz comienza también cuando uno aprende a perdonar, eso es muy importante. Los colombianos, por haber vivido tanto tiempo en guerra, se nos había olvidado perdonar y fuimos acumulando resentimientos o visiones de la guerra poco a poco, en el subconsciente 
muchas veces, que nos hace muchas veces ser mucho más duros [...]". La construcción de intertextos se formula desde la combinación de recursos como las metáforas con función de interpelación axiológica y como recurso de racionalización modal, la construcción de proporcionalidades inversas y formas de inclusión a través de recursos pronominales y verbales en primera persona del plural.

En la construcción metafórica del corazón como el lugar en el que es posible hallar la paz se activan relatos instalados en la cultura occidental e intertextos desde los que se formula la idea del corazón como el lugar de la vida, las emociones, los sentimientos y los deseos. Estas representaciones del corazón adquieren un lugar central en la narrativa, toda vez que designan el lugar en el que es posible verificar las cualidades afectivas y morales de las personas y formas de valorar, sentir y ser en un mundo estructurado por interrelaciones con otros. La activación del intertexto del corazón como centro de las emociones y los deseos refuerza la función modal del relato, que se postula como una enseñanza, un conocimiento trascendente de la vida y una intuición oculta y misteriosa que se revela al entendimiento humano, que se supone conduce al desarrollo moral de la nación. En la representación metafórica del corazón, se refuerza el sentido de la responsabilidad individual, ya que se le asigna a cada sujeto la obligación indirecta de transformar su condición emocional y se establece una causalidad entre el proceso reflexivo de introspección y la construcción de la paz.

La evocación de la metáfora del corazón se constituye en el recurso semiótico que le permite a Juan Manuel Santos introducir el tema del perdón como una segunda fase del proceso de introspección reflexiva que se propone como requisito para la paz, desde lo cual se postula la idea de corrección del devenir afectivo que hace parte de la historia de violencia del país. Esta construcción discursiva sugiere que la modificación de las disposiciones afectivas redundarían en la modificación del curso de una historia construida por individuos que han guiado sus acciones por resentimiento. El proceso de racionalización que se deriva de la evocación de la metáfora del corazón y las formas de interpelación axiológica que se llevan a cabo a través de la narrativa reorientan la discusión sobre las relaciones colectivas y las tensiones sociales, hacia emociones valoradas negativamente, en razón de las cuales es posible la segmentación de la experiencia de los sujetos victimizados entre el perdón y la reconciliación, y el rencor y la guerra. 
Formación de la identidad "víctima" en el discurso del presidente

La internalización del ideario en torno al perdón y la reconciliación en el discurso presidencial se revaloriza como resultado de la conceptualización de la paz como efecto de un saber religioso y de la reorientación moral, todo lo cual se sujeta a la agencialidad individual, que permitiría sustituir emociones inherentes a los procesos de normalización de la guerra. El expresidente elabora, de esta manera, la construcción de un estadio pre-racional, subconsciente, en el que se ubicarían los sujetos cuyas disposiciones emocionales no se ajustan al patrón religioso, moral y afectivo propuesto, y un estadio superior en el que se ubican sujetos cuyas voces pueden ser valorizadas en razón de su superioridad moral: "Todas esas Víctimas son las que nos van a señalar el camino al resto, a decir miren nosotros estuvimos en la guerra, sufrimos la guerra pero fuimos capaces [...] de perdonar, fuimos capaces de rehacer nuestras vidas, fuimos capaces de dejar atrás ese inmenso dolor [...] para que todos juntos podamos trabajar hacia adelante por un mejor país". En estas construcciones discursivas se formula el lugar de los sujetos victimizados idealizados en concordancia con el marco moral propuesto y sus voces, indirectamente modeladas, se formulan como corolario de la definición de un prospecto de futuro abstracto: "un mejor país".

\section{Conclusión}

El periodo en el cual el expresidente Juan Manuel Santos formuló y validó el modelo de justicia transicional que se derivó de las negociaciones entre el Estado, las FARC y otros actores sociales, es crucial para entender cómo la explicación neoliberal del conflicto y la paz se impuso en la agenda pública, a través de los discursos de los actores que tenían mayor capacidad para tematizar asuntos cruciales en dicha agenda. En la representación de las víctimas como sujetos inocentes, generosos y con la obligación de perdonar se perfila la construcción de la idea de que el ciudadano que ha sido victimizado tiene la responsabilidad individual de cohonestar los valores dominantes, para ser incluido en el grupo de quienes gozarían de reconocimiento y cuyas demandas tendrían una mayor audibilidad social y política. 
Juan Ruiz Celis

Las víctimas que descreen de la reconciliación como el modelo ideal para la construcción de una paz incluyente, así como las que demandan la satisfacción de consignas históricas de reparación material, igualdad, memoria y justicia, son controvertidas moralmente y ubicadas en el espectro de una otredad beligerante y desconsiderada respecto al deber colectivo de construir paz. La formación semiótico-discursiva de la identidad de la víctima en los discursos de Santos tuvo la función de construir un orden simbólico basado en una moralidad en la que el individuo es responsable de sí y de los demás y, por consiguiente, se debe esforzar incluso a través de actos de renuncia de la parte de los derechos colectivos que riñan con los ideales individuales que integran el consenso político de las élites promotoras del modelo de justicia transicional basado en la reconciliación.

La promoción del perdón y la reconciliación como referentes de construcción de la paz ubican la discusión en el plano subjetivo de las disposiciones, las conductas y las emociones de los individuos. Esto, desde el punto de vista de los discursos del expresidente Santos, habilita al conjunto de sujetos capaces de asumir como responsabilidad propia el perdón a sus ofensores, para ser tomados en cuenta como autoridades morales susceptible de ser imitadas por el resto de los miembros de la sociedad. En este sentido, la discusión sobre la garantía de los derechos de los sujetos victimizados es suplantada por consideraciones alrededor de la idea de mérito. Según esta idea, solo quienes se esfuerzan demostrando su inocencia, siendo generosos y perdonando pueden tener acceso a la restitución de sus derechos, lo cual da lugar a una política de reconocimiento diferencial con amplios efectos desigualadores, entre los distintos sectores de víctimas.

\section{Juan Ruiz Celis}

Politólogo por la Universidad Nacional de Colombia, especialista en Planificación y Gestión en Políticas Sociales por la Universidad de Buenos Aires y candidato a maestro en Políticas Sociales por la Universidad de Buenos Aires. Miembro del Grupo Colombiano de Análisis de Discurso Mediático e investigador del proyec- 
Formación de la identidad "víctima" en el discurso del presidente

to Questioning Traumatic Heritage: Spaces of Memory in Europe, Argentina and Colombia (sPeme), financiado por la Unión Europea.

\section{Obras citadas}

Butler, Judith. Mecanismos psíquicos del poder. Madrid: Ediciones Cátedra. 2001. Impreso.

Chilton, Paul y Schäffner, Christina. "Discurso y política" Teun van Dijk. El discurso como internacción social. Barcelona: Gedisa. 2000. Impreso.

Fairclough, Norman. "El análisis crítico del discurso como método para la investigación en ciencias sociales”. Métodos de análisis crítico del discurso Eds. Ruth Wodak y Michael Meyer. Barcelona: Gedisa. 2003. Impreso.

Fairclough, Isabela y Norman Fairclough. Political Discourse Analysis: A Method for Advanced Students. Londres: Routledge. 2012. Impreso.

Foucault, Michel. La arqueología del saber. Buenos Aires: Siglo xxi Editores. 2008. Impreso.

Gómez-Muller, Alfredo. La reconstrucción de Colombia. Escritos políticos. Medellín: La Carreta Editores. 2008. Impreso.

Kress, Gunther y van Leeuwen, Theo. Multimodal discourse. The modes and media of contemporary communication. London: Arnold. 2000. Impreso.

Mercado, Asael y Hernández, Alejandrina. El proceso de construcción de la identidad colectiva. Convergencia. Revista de Ciencias Sociales 53, mayo-agosto (2010). 229-251. Web. < https://convergencia.uaemex.mx/article/view/1150>

Pardo Abril, Neyla. Cómo hacer análisis crítico del discurso. Una perspectiva Latinoamericana. Bogotá: Universidad Nacional de Colombia, 2014. impreso.

Pardo, Neyla y Ruiz, Juan. "Pobreza y bienestar en Colombia. Prácticas mediáticas y políticas discursivas”. Pobreza en la prensa hegemónica de Colombia, Argentina 
y Brasil. Eds. Sonia Álvarez y Norma Naharro. Buenos Aires: Consejo Latinoamericano de Ciencias Sociales (CLACSO), 2018. Impreso.

Pardo, Neyla y Ruiz, Juan. "Pobreza y bienestar en Colombia. Construcción de referenciales en perspectiva mediática". Pobreza, Lenguaje y Medios en América Latina. Ana Chiquito y Gabriel Quiroz. Frankfurt: Peter Lang, 2017. Impreso.

Roth, André-Noël. Políticas públicas. Formulación implementación y evaluación. Bogotá: Ediciones Aurora, 2009. Impreso.

Sánchez, Gonzalo. Guerras, Memoria e Historia. Medellín: La Carreta Editores, 2009. Impreso.

Santos, Juan Manuel. Discurso. Web. <https://id.presidencia.gov.co/sala-de-prensa/ discursos>

Teitel, Ruti. Transicional justice genealogy. Harvard Human Rights Journal 16, Spring (2003). 69-94. Impreso.

Van Dijk, Teun. Discurso y contexto. Barcelona: Gedisa, 2011. Impreso.

Van Dijk, Teun. Sociedad y discurso. Barcelona: Gedisa, 2010. impreso.

Van Dijk, Teun. Discurso y poder. Barcelona: Gedisa, 2009. Impreso.

Wodak, Ruth. "El enfoque histórico del discurso" Métodos de análisis crítico del discurso. Eds. Ruth Wodak y Michael Meyer. Barcelona: Gedisa, 2003. Impreso. 